\title{
Correction to: Studies on heavy mineral placers from eastern coast of Odisha, India by instrumental neutron activation analysis
}

\author{
Rahat Khan ${ }^{1}$ - Shayantani Ghosal ${ }^{2} \cdot$ Debashish Sengupta $^{2}$ - Umma Tamim ${ }^{1} \cdot$ Syed Mohammod Hossain ${ }^{1,3}$. \\ Sudha Agrahari ${ }^{2}$
}

Published online: 13 November 2018

๑) Akadémiai Kiadó, Budapest, Hungary 2018

\section{Correction to: \\ Journal of Radioanalytical and Nuclear Chemistry https://doi.org/10.1007/s10967-018-6250-1}

The original article was published without an acknowledgement section. The complete acknowledgement section is given below.

Acknowledgements The work has been funded by the Science and Engineering Research Board (SERB), DST, Govt. of India, under the Project Code: YSS/2015/000979. We acknowledge their financial assistance. We are also thankful to the technical personnel associated with this study, especially to the persons involved in the TRIGA Mark II research reactor operation at the Center for Research Reactor, AERE, Bangladesh Atomic Energy Commission, Bangladesh.

The original article can be found online at https://doi.org/10.1007/ s10967-018-6250-1.

Debashish Sengupta

dsgg@gg.iitkgp.ac.in

1 Institute of Nuclear Science and Technology, Bangladesh Atomic Energy Commission, Savar, Dhaka 1349,

Bangladesh

2 Department of Geology and Geophysics, Indian Institute of Technology Kharagpur, Kharagpur, West Bengal 721302, India

3 Human Resources Division, Bangladesh Atomic Energy Commission, E-12/A Agargaon, Sher-e-Bangla Nagar, Dhaka 1207, Bangladesh 